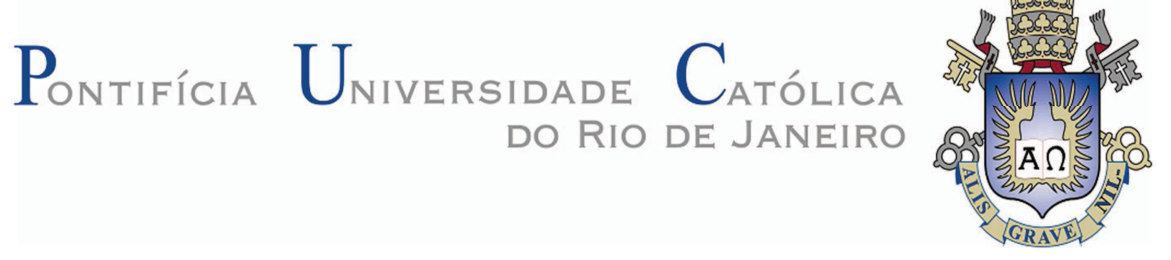

Sandra Helena Trindade Santos

\author{
Análise do Comportamento de Misturas \\ de Solos com Cinzas de Bagaço de \\ Cana-de-Açúcar e Cinzas de Casca de Arroz
}

Dissertação de Mestrado

Dissertação apresentada como requisito parcial para obtenção do grau de Mestre pelo Programa de Pós-graduação em Engenharia Civil do Departamento de Engenharia Civil da PUC-Rio.

Orientadora: Prof ${ }^{a}$ Michéle Dal Toé Casagrande

Rio de Janeiro, Março de 2015 


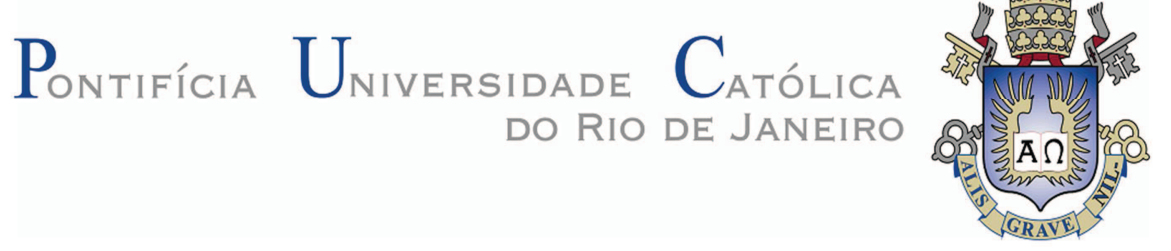

Sandra Helena Trindade Santos

\title{
Análise do Comportamento de Misturas de Solos com Cinzas de Bagaço de Cana-de-Açúcar e Cinzas de Casca de Arroz
}

Dissertação apresentada como requisito parcial para obtenção do grau de Mestre pelo Programa de Pós-Graduação em Engenharia Civil do Departamento de Engenharia Civil do Centro Técnico Científico da PUC-Rio. Aprovada pela Comissão Examinadora abaixo assinada.

\author{
Profa. Michéle Dal Toé Casagrande \\ Orientadora \\ Departamento de Engenharia Civil - PUC-Rio \\ Prof ${ }^{\mathrm{a}}$ Raquel Quadros Veloso \\ Departamento de Engenharia Civil - PUC-Rio \\ Profa Ana Cristina Castro Fontenla Sieira \\ Universidade do Estado do Rio de Janeiro
}

Prof. Guilherme Chagas Cordeiro Universidade do Estadual do Norte Fluminense

Prof. José Eugenio Leal Coordenador Setorial do Centro Técnico Científico - PUC-Rio

Rio de Janeiro, 20 de Março de 2015 
Todos os direitos reservados. É proibida a reprodução total ou parcial do trabalho sem autorização da universidade, da autora e da orientadora.

\section{Sandra Helena Trindade Santos}

Graduou-se em Engenharia Ambiental pela Universidade Federal Fluminense em 2012. Ingressou no Mestrado na Pontifícia Universidade Católica do Rio de Janeiro em 2012, desenvolvendo Dissertação na linha de pesquisa de Geotecnia Experimental.

Santos, Sandra Helena Trindade

Análise do comportamento de misturas de solos com cinzas de bagaço de cana-de-açúcar e cinzas de casca de arroz / Sandra Helena Trindade Santos; orientadora: Michéle Dal Toé Casagrande. - 2015.

125 f.; $30 \mathrm{~cm}$

Dissertação (mestrado)-Pontifícia Universidade Católica do Rio de Janeiro, Departamento de Engenharia Civil, 2015.

Inclui bibliografia

1. Engenharia civil - Teses. 2. Cinza de bagaço de cana-de-açúcar. 3. Cinza de casca de arroz. 4. Obras geotécnicas. 5. Ensaio de cisalhamento direto. I. Casagrande, Michéle Dal Toé. II. Pontifícia Universidade Católica do Rio de Janeiro. Departamento de Engenharia Civil. III. Título. 


\section{Agradecimentos}

Em primeiro lugar, gostaria de agradecer a Deus e aos meus pais que sempre me apoiaram em todas as fases da minha vida.

Agradeço, também, à CAPES pelo apoio financeiro que me permitiu realizar este estudo.

À professora e orientadora Michéle Dal Toé Casagrande, expresso minha gratidão pelo incentivo e paciência que demonstrou durante todo o período em que cursei o mestrado, pela disposição em me orientar, tanto nesta dissertação, quanto na vida acadêmica e, principalmente, pela amizade durante estes quase três anos de convívio.

Agradeço, ainda, aos meus grandes amigos Camilla Duarte, Rhaissa Rodrigues, Nathália Louzada, Giobana Rossio e Daniel da Costa por todo apoio que me foi dado durante o período no qual estudei para as matérias do mestrado, por terem compartilhado, comigo, momentos divertidos, por terem me incentivado a concluir o curso e me apoiado sempre que precisei. Sou extremamente grata pela paciência e pela amizade de todos vocês.

Também agradeço aos demais amigos que estiveram ao meu lado durante todo o curso, dentre eles, Luciana Szeliga, Júlia Carneiro, Amanda Crispim, Juan Manuel, Orlando Rojas, Adriano Malko, Fernando Azevedo. Esses queridos amigos estiveram comigo em momentos de alegria e tensão que passamos ao longo do curso, seja nos churrascos e saídas que sempre renderam boas risadas, seja nos momentos de estudo e nervosismo pré-provas.

Sou grata ao meu amigo e namorado Wagner, pelo apoio, pela paciência, por todos os momentos felizes que temos passado e, principalmente, pelo carinho e amor que recebo os quais me fazem uma pessoa mais feliz a cada dia. Ah, não 
posso deixar de agradecer por você ter perdido vários finais de semana me mandando estudar.

Concluir esse curso foi muito difícil, mas seria impossível sem a ajuda de todos aqui citados, por isso, sou eternamente grata a vocês. 


\section{Resumo}

Santos, Sandra Helena Trindade; Casagrande, Michéle Dal Toé. Análise do Comportamento de Misturas de Solos com Cinzas de Bagaço de Cana-de-Açúcar e Cinzas de Casca de Arroz. Rio de Janeiro, 2015. 125 p. Dissertação de Mestrado - Departamento de Engenharia Civil, Pontifícia Universidade Católica do Rio de Janeiro.

Apresenta-se o estudo experimental do comportamento de um solo arenoso e de um solo argiloso, reforçado e não reforçado com cinza de bagaço de cana-deaçúcar e com cinza de casca de arroz, por meio da realização de ensaios de caracterização física e química e de ensaios de cisalhamento direto. Busca-se estabelecer padrões de comportamento que possam explicar a influência da adição das cinzas, relacionando-os com os parâmetros de resistência ao cisalhamento e de deformação do solo. Os ensaios foram realizados em amostras com teores que variaram entre $5-20 \%$. Por meio dos resultados obtidos, foi possível concluir que a inserção de cinza de bagaço de cana-de-açúcar, aos solos argiloso e arenoso em estudo, mostra-se viável, uma vez que resultaram em melhoria dos parâmetros de resistência ou não causaram alterações significativas. Para a cinza de casca de arroz, em misturas com solo arenoso, a aplicação não se mostrou viável, visto que, para ambos os teores de cinza, houve um decréscimo no ângulo de atrito e nenhum acréscimo de coesão. Nas misturas com solo argiloso, a aplicação da mesma cinza mostrou-se viável, haja vista que sua aplicação resultou em melhoria dos parâmetros de resistência. Quanto ao teor de cinza para as misturas com solo argiloso, verificou-se que o melhor comportamento obtido foi com o teor de $20 \%$, para as misturas com ambas as cinzas. Para as misturas com areia, como não houve um aumento proporcional da resistência com o aumento do teor das cinzas foi difícil determinar um teor ótimo de cinza a ser utilizado. Os resultados obtidos neste estudo, em geral, mostraram-se satisfatórios e cumpriram os objetivos iniciais propostos com relação à investigação do comportamento solo-cinza para utilização em obras geotécnicas.

\section{Palavras-chave}

Cinza de bagaço de cana-de-açúcar, cinza de casca de arroz, obras geotécnicas, ensaio de cisalhamento direto. 


\section{Abstract}

Santos, Sandra Helena Trindade; Casagrande, Michéle Dal Toé (Advisor). Analysis of Soil Mixtures Behavior with Sugarcane Bagasse Ashes and Rice Husks Ashes. Rio de Janeiro, 2015. 125 p. MSc. Dissertation Departamento de Engenharia Civil, Pontifícia Universidade Católica do Rio de Janeiro.

This paper presents the experimental study of the behavior of a sandy soil and a clay soil, reinforced and unreinforced with sugarcane bagasse ash and rice husk ash, by performing physical and chemical characterization tests and direct shear tests. The aim is to establish patterns of behavior that may explain the influence of the addition of ashes, relating them to the shear strength parameters and soil deformation. The tests were carried out on samples with concentrations ranging from $5-20 \%$. Through the results, it was possible to conclude that the inclusion of sugarcane bagasse ash, to clay and sandy soils under study, proves viable, since it resulted in improved strength parameters or did not cause significant alterations. For the rice husk ash in mixtures with sandy soil, the application was not feasible, since for both ash contents there was a decrease in the friction angle and no increase in the cohesion. In blends with clay soil, the application of the same ash proved to be feasible, given that its application resulted in improvement of resistance parameters. As for the ash content for mixtures containing clay soil, it was found that the best performance was obtained with $20 \%$ content for mixtures with both ashes. For mixtures with sand, as there was not a proportional increase in resistance with increasing content of ash it was difficult to determine an optimal ash content to be used. The results of this study generally were satisfactory and met the initial proposed objectives in relation to soil-ash behavioral research for use in geotechnical works.

\section{Keywords}

Sugarcane bagasse ash; rice husk ash; geotechnical works; direct shear test. 


\section{Sumário}

1 Introdução 18

$\begin{array}{ll}\text { 1.1. Relevância da pesquisa } & 18\end{array}$

1.2. Objetivos 19

1.3. Organização do trabalho 20

2 Revisão Bibliográfica $\quad 21$

2.1. Considerações iniciais 21

2.2. Cinza de bagaço de cana-de-açúcar 22

2.2.1. Aplicações de cinza de bagaço de cana-de-açúcar 24

$\begin{array}{ll}\text { 2.3. Cinza de casca de arroz } & 27\end{array}$

đิ 2.3.1. Aplicação de cinza de casca de arroz 29

2.4. Estabilização de solos 32

2.4.1. Estabilização mecânica $\quad 35$

2.4.2. Estabilização física 35

2.4.3. Estabilização química 36

2.5. Considerações finais 45

3 Programa Experimental 46

3.1. Materiais utilizados 46

$\begin{array}{lll}3.1 .1 & \text { Areia } & 47\end{array}$

$\begin{array}{lll}3.1 .2 & \text { Solo argiloso } & 48\end{array}$

3.1.1. Água 50

3.1.2. Cinza de bagaço de cana-de-açúcar $\quad 50$

3.1.3. Cinza de casca de arroz

3.1.4. Cinza de bagaço de cana-de-açúcar e cinza casca de arroz ultrafinas 53

3.1.5. Misturas solo-cinza 53

3.2. Métodos e procedimentos de ensaio 55

3.2.1. Ensaios de caracterização física 56

3.2.2. Ensaios de caracterização química 60

3.2.3. Ensaio de caracterização mecânica 60 
4 Resultados e Análises $\quad 71$

4.1 Ensaios de caracterização física 71

4.1.1. Areia 71

4.1.2. Solo argiloso puro $\quad 72$

4.1.3. Cinza de bagaço de cana-de-açúcar e misturas $\quad 74$

4.1.4. Ensaios químicos $\quad 78$

4.1.5. Cinza de casca de arroz e misturas $\quad 84$

4.1.6. Ensaios químicos $\quad 87$

4.2. Ensaio de caracterização mecânica 92

4.2.1. Solo argiloso 92

4.2.2. Solo arenoso 103

4.3. Considerações sobre os resultados 113

5 Considerações Finais 115

5.1. Conclusões 115

$\begin{array}{ll}\text { 5.2. Sugestões para pesquisas futuras } & 117\end{array}$

6 Referências Bibliográficas $\quad 119$ 


\section{Lista de figuras}

Figura 1 Esquema global do processo de produção de açúcar e álcool (Cordeiro, 2006)

Figura 2 Fluxograma simplificado do beneficiamento industrial do arroz

(CORDEIRO, 2006) 28

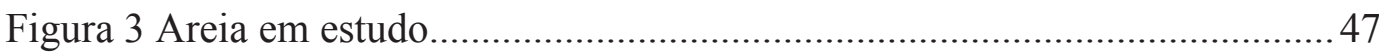

Figura 4 Local de coleta do material na praia da Barra da Tijuca - RJ ................. 47

Figura 5 Localização do Campo Experimental II PUC-Rio (Soares 2005) .......... 49

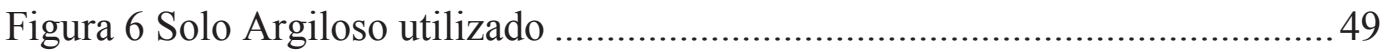

Figura 7 Cinza de Bagaço de Cana-de-açúcar........................................................50

Figura 8 Pilha cônica e alongada, utilizada na homogeneização e no quarteamento da cinza residual do bagaço de cana-de-açúcar (Fonte Cordeiro,2006) 51

Figura 9 Bagaço de cana-de-açúcar (a) e diferentes cinzas residuais geradas após a queima do bagaço em caldeira: cinza escura, com alto teor de carbono, característico de combustão incompleta (b), cinza, com menor teor de carbono (c), e cinza gerada após combustão completa (d). (Fonte Cordeiro 2006) .52 Figura 10 Indústria de Beneficiamento de Arroz Urbano agroindustrial, localizada em Jaraguá do Sul/SC. Fotografias dos silos de armazenagem do arroz (a) e da planta industrial (b) (Fonte Cordeiro, 2006)......................................................5 52

Figura 11 Representação gráfica do critério de ruptura de Mohr-Coulomb..........6 64 Figura 12 Esquema do equipamento do ensaio de cisalhamento direto com deformação controlada (Gerscovich, 2010, apud Benedetti, 2011) 65 Figura 13 Moldagem dos corpos de prova do solo puro e solo-cinza - casca de arroz para ensaio

Figura 14 Caixa de cisalhamento direto

Figura 15 Prensa utilizada para a realização do ensaio de cisalhamento direto.

Laboratório de Geotecnia/PUC-Rio 69

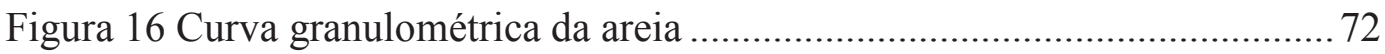

Figura 17 Gráfico de determinação do Limite de Liquidez................................... 73

Figura 18 Curvas granulométricas obtidas para solo argiloso puro ..................... 74

Figura 19 Curvas granulométricas do solo arenoso, cinza de bagaço de cana-de- 
açúcar e misturas do solo com 5, 10 e 20\% de cinza. 76

Figura 20 Curvas granulométricas do solo argiloso, cinza de bagaço de cana-deaçúcar e misturas do solo com $10 \%$ e $20 \%$ de cinza

Figura 21 Curvas granulométricas do solo arenoso, cinza de casca de arroz e misturas do solo com 10 e $20 \%$ de cinza.

Figura 22 Curvas granulométricas do solo argiloso, cinza de casca de arroz e misturas do solo com $10 \%$ e $20 \%$ de cinza 86

Figura 23 Curvas de compactação do solo puro e das misturas com cinza de bagaço de cana-de-açúcar e com cinza de casca de arroz 93

Figura 24 Curva tensão cisalhante $\mathrm{x}$ deslocamento horizontal solo argiloso .........94

Figura 25 Curva tensão cisalhante x deslocamento horizontal Bc10Argila90 ...... 95

Figura 26 Curva tensão cisalhante $\mathrm{x}$ deslocamento horizontal Bc20Argila80 ...... 95

Figura 27 Curva tensão cisalhante $\mathrm{x}$ deslocamento horizontal solo argiloso puro e com teores de cinza de bagaço de cana-de-açúcar 96

Figura 28 Envoltórias de ruptura do solo argiloso puro e com teores de cinza de bagaço de cana-de-açúcar

Figura 29 Curva tensão cisalhante x deslocamento horizontal solo argiloso puro 99 Figura 30 Curva tensão cisalhante $\mathrm{x}$ deslocamento horizontal Ca10Argila90 .... 100 Figura 31 Curva tensão cisalhante $\mathrm{x}$ deslocamento horizontal Ca20Argila80 .... 100 Figura 32 Curva tensão cisalhante $\mathrm{x}$ deslocamento horizontal do solo argiloso puro e com teores de cinza de casca de arroz..... 101 Figura 33 Envoltórias de ruptura do solo argiloso puro e com teores de cinza de casca de arroz

Figura 34 Curvas tensão cisalhante $\mathrm{x}$ deslocamento horizontal para areia 104

Figura 35 Curvas tensão cisalhante $\mathrm{x}$ deslocamento horizontal para Bc5Areia95

Figura 36 Curvas tensão cisalhante x deslocamento horizontal para Bc10Areia90 105

Figura 37 Curvas tensão cisalhante $\mathrm{x}$ deslocamento horizontal para Bc20Areia80 105

Figura 38 Curvas tensão cisalhante $\mathrm{x}$ deslocamento horizontal para areia pura e com teores de cinza de bagaço de cana-de-açúcar 106 Figura 39 Envoltórias de ruptura da areia pura e com teores de cinza de bagaço de 
cana-de-açúcar 107

Figura 40 Curvas tensão cisalhante $\mathrm{x}$ deslocamento horizontal para a areia....... 108 Figura 41 Curvas tensão cisalhante x deslocamento horizontal Ca10Areia90.... 109 Figura 42 Curvas tensão cisalhante $\mathrm{x}$ deslocamento horizontal Ca20Areia80.... 109 Figura 43 Curvas tensão cisalhante $\mathrm{x}$ deslocamento horizontal da areia e de misturas com teores de cinza de casca de arroz 110

Figura 44 Envoltórias de ruptura da areia pura e com teores de cinza de casca de arroz 111 


\section{Lista de Tabelas.}

Tabela 1 Símbolos utilizados para os solos e misturas...........................................55

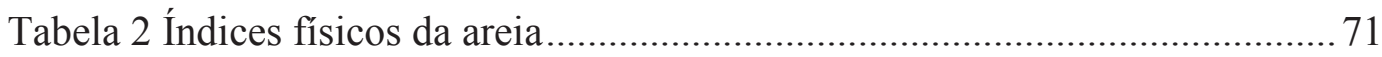

Tabela 3 Resultados do ensaio de densidade real dos grãos para areia, cinza de

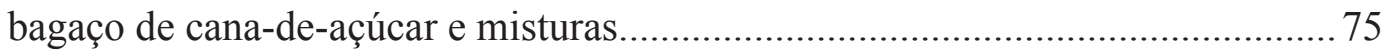

Tabela 4 Resultados do ensaio de densidade real dos grãos para o solo argiloso, cinza de bagaço de cana-de-açúcar e misturas ....................................................... 75

Tabela 5 Elementos químicos presentes na cinza de bagaço de cana-de-açúcar... 78 Tabela 6 Composições químicas das cinzas estudadas por Martirena Hernández et al. (1998), Massazza (1998) e Singh et al. (2000).............................................. 79

Tabela 7 Composição química em termos de óxidos por espectrometria de fluorescência de raios $\mathrm{X}$ 80

Tabela 8 Resultados analíticos dos ensaios de lixiviação - parâmetros orgânicos (TASQA, 2014)

Tabela 9 Resultados analíticos dos ensaios de lixiviação - parâmetros inorgânicos (TASQA, 2014) 82

Tabela 10 Resultados analíticos dos ensaios de solubilização - parâmetros orgânicos (TASQA, 2014).

Tabela 11 Resultados analíticos dos ensaios de solubilização - parâmetros inorgânicos (TASQA, 2014).

Tabela 12 Resultados do ensaio de densidade real dos grãos para a areia, cinza de casca de arroz e misturas 84

Tabela 13 Resultados do ensaio de densidade real dos grãos para o solo argiloso, cinza de casca de arroz e misturas 84

Tabela 14 Elementos químicos presentes na cinza de casca de arroz 87

Tabela 15 Composição química da cinza de casca de arroz por Martirena Hernández et al. (1998) .88

Tabela 16 Composição química por espectrometria de fluorescência de raios X. 88 Tabela 17 Tabela: Resultados analíticos dos ensaios de lixiviação - parâmetros orgânicos (TASQA, 2014). 89

Tabela 18 Resultados analíticos dos ensaios de lixiviação - parâmetros inorgânicos (TASQA, 2014). 
Tabela 19 Resultados analíticos dos ensaios de solubilização parâmetros orgânicos (TASQA, 2014) 91

Tabela 20 Resultados analíticos dos ensaios de solubilização - parâmetros inorgânicos (TASQA, 2014).

Tabela 21 Parâmetros de Resistência do solo argiloso puro e com teores de cinza de bagaço de cana-de-açúcar ................................................................................98 Tabela 22 Parâmetros de Resistência do solo puro e com teores de cinza de casca de arroz 102

Tabela 23 Parâmetros de Resistência da areia pura e com teores de cinza de bagaço de cana-de-açúcar

Tabela 24 Parâmetros de Resistência da areia pura e com teores de cinza de casca de arroz

Tabela 25 Comparação da variação dos parâmetros de resistência para misturas com solo arenoso Tabela 26 Comparação da variação dos parâmetros de resistência para misturas com solo argiloso. 


\section{Lista de abreviaturas}

ABNT

$\mathrm{Bc}$

$\mathrm{Ca}$

CONAMA

$\mathrm{CH}$

EDX

IP

LL

LP

LVDT

ML

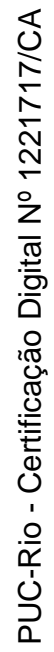

Associação Brasileira de Normas Técnicas

Cinza de Bagaço de cana-de-açúcar

Cinza de casca de arroz

Conselho Nacional do Meio Ambiente

Argila arenosa de média plasticidade

Espectrometria de fluorescência de raios-X

Índice de Plasticidade

Limite de Liquidez

Limite de Plasticidade

Linear Variable Differential Transformer

Silte de baixa plasticidade

Norma brasileira

Pontifícia Universidade Católica

Resíduos sólidos urbanos

Areia siltosa

Sistema Unificado de Classificação dos Solos 


\section{Lista de símbolos}

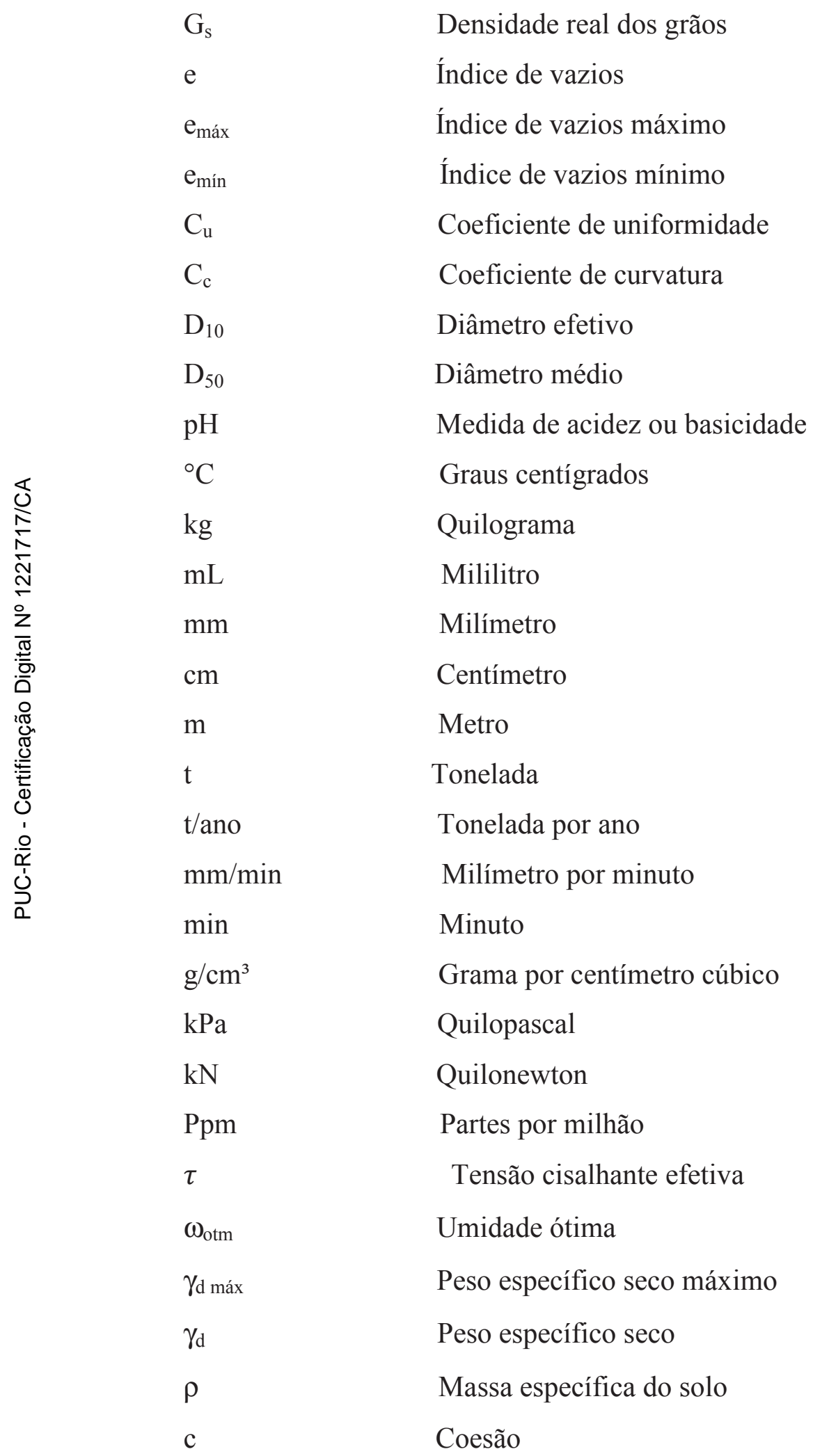




$$
\begin{aligned}
& \varnothing^{\prime} \\
& \sigma^{\prime}
\end{aligned}
$$

Ângulo de atrito

Tensão normal efetiva

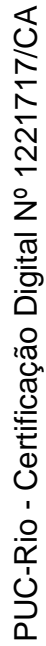

